\title{
EFFECT OF VARIOUS CONCENTRATIONS OF LIGNOCAINE \& ADRENALINE COMBINATION AS LOCAL ANESTHETIC ON ECG PARAMETERS OF PATIENTS UNDERGOING DENTAL PROCEDURES
}

\author{
Sinare BR ${ }^{1}$, Annasaheb Gagare ${ }^{2}$, Chinmaye Batwal ${ }^{3}$, Liz Thaliath ${ }^{3}$, Prashant Patel ${ }^{4}$, Kunkulol RR ${ }^{5}$, Narwane Sandeep \\ ${ }^{1,2}$ Assistant Professor, Department of Medicine, ${ }^{3}$ Research Associate, Rural Medical College, \\ Pravara Institute of Medical Sciences (Deemed University), Maharashtra. \\ ${ }^{4}$ Assistant Professor, ${ }^{5}$ Professor, ${ }^{6}$ Associate Professor, Department of Pharmacology, \\ Rural Medical College, Pravara Institute of Medical Sciences (Deemed University) Loni, Maharashtra.
}

\section{ABSTRACT}

Background: Systemic absorption of local anesthetics occurs due to its local vasodilator effects. This leads to inhibitory action on the heart which is represented in the form of a decrease in conduction rate, the excitability of myocardium and force of contraction. The aim of the present study was to evaluate the effects of Lignocaine and adrenaline combinations on electrocardiogram undergoing dental procedures. Methods: This was a prospective, observational clinical study done in collaboration with the Department of Oral \& Maxillofacial Surgery. All patients scheduled for oral surgeries under local anesthesia with Lignocaine $2 \%$ and adrenaline (1:80000 or 1:200000) combination of age 18 years or above 150 patients were included in the study. Patients with a history of hepatic, renal, cardiovascular and thyroid disorders were excluded from the study. A standard 12-lead ECG $(25 \mathrm{~mm} / \mathrm{s})$ was recorded for each patient before administration of drugs (Basal), during the dental procedure (Intraoperative) and immediately after completion of surgical procedure. Results: There was no statistically significant difference seen between the Group A (Lignocaine $2 \%$ with 1:80000 adrenaline) and B (Lignocaine $2 \%$ with 1:200000 adrenaline) when the age, gender, PR interval, RR interval, mean QT \& QTc dispersion, and heart rate were compared. Statistically significant difference was seen in comparing the mean QT \& QTc interval, which was higher in Group A. ECG parameters in Group A and B showed a statistically significant decrease in PR interval, RR interval, QT interval, QTc interval, QT dispersion and QTc dispersion, with the basal, was compared with intraoperative and postoperative findings. The increase in heart rate although was statistically significant in both the groups, it was always within normal limits suggestive of no clinical significance. There was a statistically significant decrease in QT and QTc interval, QT and QTc dispersion. The change in all these parameters was within the physiologic range. All these relevant parameters for cardiac arrhythmias did not show any arrhythmogenic potential of lignocaine-adrenaline combination in both the groups. Both the combinations are comparable with each other in terms of ECG parameters with changes more with group A suggesting the effect of increased concentration of adrenaline. The change in the heart rate and ECG parameters in both the study group might be attributed to the presence of adrenaline in the combination. No cardiovascular morbidities were observed except palpitation. Conclusion: Thus it can be very well concluded that the effects of lignocaine-adrenaline combinations on electrocardiographic parameters are minimal and clinically irrelevant. Both the combination appears to be safe to use in healthy individuals.

Keywords: Adrenaline; Lignocaine; ECG parameters; Dental procedures

\section{INTRODUCTION}

Local anesthetics reversibly block the voltage sensitive Sodium channels that lead to inhibition of action potential of all excitable membranes. When local anesthetics are inadvertently injected into circulation, the central nervous system and the cardiovascular system become

susceptible to its action $[1,2]$. Systemic absorption also occurs due to its local vasodilator effects. This leads to inhibitory action on heart which is represented in the form of decrease in conduction rate, excitability of myocardium and force of contraction [2-4]. Local anesthetics are also known to cause cardiovascular collapse and

DOI: $10.31878 /$ ijcbr.2019.52.07

death due to its arteriolar dilatory action and sudden onset ventricular fibrillation [3].

Adrenaline is most commonly used vasoconstrictor in dental surgeries in varying concentration like 1:80000, $1: 100000,1: 200000$. Adrenaline is also absorbed from the site of injection, just as is the local anesthetic. The adrenaline levels in plasma raise after injecting of 1.8 $\mathrm{ml}$ of Lignocaine with 1:100000 adrenaline as a local anesthetic [5-7]. The aim of present study was to evaluate effects of Lignocaine and adrenaline combinations on electrocardiogram undergoing dental procedures.

\section{MATERIALS AND METHODOLOGY}

Study design: This was a prospective, observational clinical study

Ethics approval: Study was approved by the Institutional ethics committee and written informed consent

Correspondence: Dr. Annasaheb Gagare, Assistant Professor, Department of Medicine, Rural Medical College, Loni, Pravara Institute of Medical Sciences (DU) Email: director.research@pmtpims.org 
were taken from the participants.

Place of research: The study was done in collaboration with the Department of Oral \& Maxillofacial Surgery, Rural Dental College \& Hospital, Loni.

Study population: Patients planned for various oral surgeries under local anesthesia were enrolled for the study according to eligibility criteria.

Inclusion criteria: All patients scheduled for oral surgeries under local anesthesia with Lignocaine and adrenaline combination of age 18 years or above of either gender

Exclusion criteria: Patients with history of hepatic, renal, cardiovascular and thyroid disorders were excluded from the study.

Sample size: 150 patients planned for dental surgeries under anesthetic cover of lignocaine and adrenaline combination were selected.

Grouping: In all the patients, concentration of lignocaine was constant $(2 \%)$. So patients were grouped according to the concentration of Adrenaline used:

Group A: Lignocaine 2\% \& Adrenaline 1:80000

Group B: Lignocaine 2\% \& Adrenaline 1:200000

Drug administration: $1.8 \mathrm{ml}$ as single dose. The drugs in both the groups are used as a Fixed Dose Combination (FDC).

Methodology: The Demographic Profile of patients was recorded. A standard 12-lead ECG $(25 \mathrm{~mm} / \mathrm{s})$ was recorded for each patient before administration of drugs (Basal), during dental procedure (Intraoperative) and immediately after completion of surgical procedure. ECG was recorded by same individual and same machine for a patient. The ECGs were analyzed qualitatively and quantitatively including measurements of the $\mathrm{PR}, \mathrm{RR}$ and QT Interval. QTc interval was calculated by using the formulae of Bazett [8]. Any adverse effect in terms of cardiovascular morbidity was also noted. Comparison of changes of all parameters between both groups was done.

Statistical Analysis: All ordinal data like age and sex were analyzed by applying Chi-square test and weight of the patients by Student's Unpaired ' $t$ ' test. Comparison of mean heart rate and all ECG parameters within the group was done by applying Friedman's test (Nonparametric Repeated Measures ANOVA test) while inter-group comparison was done by applying Student's Unpaired ' $\mathrm{t}$ ' test.

\section{RESULTS}

Table 1: Age wise Distribution of Patients on Lignocaine-Adrenaline Combinations under Study

\begin{tabular}{l|l|l|l}
\hline $\begin{array}{l}\text { *Age (yrs)/ } \\
\text { ^Gender }\end{array}$ & $\begin{array}{l}\text { Group A } \\
\text { n (\%) }\end{array}$ & $\begin{array}{l}\text { Group B } \\
\text { n (\%) }\end{array}$ & $\begin{array}{l}\text { Total } \\
\mathbf{n}(\%)\end{array}$ \\
\hline $18-40$ & $28(37.33)$ & $22(29.33)$ & $50(33.33)$ \\
\hline $41-60$ & $32(42.67)$ & $35(46.67)$ & $67(44.67)$ \\
\hline$>60$ & $15(20)$ & $18(24)$ & $33(22)$ \\
\hline Male & $35(46.67)$ & $46(61.33)$ & $81(54)$ \\
\hline Female & $40(53.33)$ & $29(38.67)$ & $69(46)$ \\
\hline
\end{tabular}

*Value of $\chi^{2}=1.127$, d.f. $=2, p>0.05$, not significant after applying Chi-square test, there was no significant association between ages of the patients of Group A and Group B.

${ }^{\wedge}$ Value of $\chi^{2}=3.247$, d.f. $=1, \mathrm{p}>0.05$, not significant, after applying Chi-square test, there was no significant association between gender of the patients of both the groups.

Table 2: Dental procedures performed using Lignocaine and Adrenaline combination

\begin{tabular}{l|l|l}
\hline Procedure & $\begin{array}{l}\text { Group A } \\
\text { n (\%) }\end{array}$ & $\begin{array}{l}\text { Group B } \\
\text { n (\%) }\end{array}$ \\
\hline Dental Extraction & $14(18.67)$ & $58(77.33)$ \\
\hline Impaction & $14(18.67)$ & $8(10.67)$ \\
\hline Alveoplasty & $26(36.67)$ & $2(2.67)$ \\
\hline $\begin{array}{l}\text { Incision \& Drainage } \\
\text { of Abscess }\end{array}$ & $9(12)$ & $7(9.33)$ \\
\hline $\begin{array}{l}\text { Mandibular Fracture } \\
\text { Fixation }\end{array}$ & $12(16)$ & 0 \\
\hline
\end{tabular}

Group A: Lignocaine 2\% + Adrenaline 1:80000,

Group B: Lignocaine 2\% + Adrenaline 1:200000

The Dental procedures commonly done were Dental extraction followed by impaction and alveoplasty (Table no. 2). Most commonly used concentration of lignocaine was $2 \%$ and for adrenaline it was 1:80000 and $1: 200000$.

Heart rate: On comparing the mean heart rate of patients of Group A and B by applying Student's Unpaired ' $t$ ' test, there was no significant difference seen at basal, intraoperative and postoperative $(p>0.05)$. By applying Friedman test (Non-parametric Repeated Measures ANOVA test), there was highly significant increase in mean values of Heart rate when Basal compared to Intraoperative and Postoperative $(p<0.0001)$ in both groups.

PR interval: By applying Student's Unpaired ' $t$ ' test, there was no significant difference between mean values of PR Interval when Group A compared to Group B at basal, intraoperative and postoperative. By applying Friedman test (Non-parametric Repeated Measures ANOVA test), there was highly significant decrease in mean values of PR Interval when Basal compared to Intraoperative and Postoperative $(p<0.0001)$ in both groups.

RR interval: By applying Student's Unpaired ' $t$ ' test, there was no significant difference between mean values of RR interval when Group A compared to Group B at basal, intraoperative and postoperative. By applying Friedman test (Non-parametric Repeated Measures ANOVA test), there was highly significant decrease in mean values of RR Interval when Basal compared to Intraoperative and Postoperative $(p<0.0001)$ in both group A and B.

QT interval: By applying Student's Unpaired ' $t$ ' test, there was no significant difference between mean values of QT interval when Group A compared to Group B at basal $(p>0.05)$, while significant difference was ob- 
Table 3: Comparison of Mean Heart Rate (per min) between Group A \& Group B at Basal, Intraoperative \& Postoperative period

\begin{tabular}{|c|c|c|c|}
\hline Parameter & & Group A & Group B \\
\hline \multirow{3}{*}{$\begin{array}{l}\text { Heart rate } \\
\text { (per min) }\end{array}$} & Basal & $88.84 \pm 7.77$ & $89.07 \pm 9.55$ \\
\hline & Intraoperative & $89.52 \pm 7.50^{*}$ & $89.47 \pm 9.24 *$ \\
\hline & Postoperative & $90.16 \pm 7.41 \#$ & $90.05 \pm 9.05 \#$ \\
\hline \multirow{3}{*}{ PR Interval } & Basal & $0.150 \pm 0.019$ & $0.149 \pm 0.021$ \\
\hline & Intraoperative & $0.147 \pm 0.018^{*}$ & $0.146 \pm 0.019^{*}$ \\
\hline & Postoperative & $0.144 \pm 0.018 \#$ & $0.143 \pm 0.018 \#$ \\
\hline \multirow{3}{*}{ RR interval } & Basal & $0.681 \pm 0.060$ & $0.681 \pm 0.072$ \\
\hline & Intraoperative & $0.675 \pm 0.057^{*}$ & $0.678 \pm 0.069^{*}$ \\
\hline & Postoperative & $0.670 \pm 0.056 \#$ & $0.673 \pm 0.067 \#$ \\
\hline \multirow{3}{*}{ QT interval } & Basal & $0.358 \pm 0.032$ & $0.348 \pm 0.034$ \\
\hline & Intraoperative & $0.353 \pm 0.031^{*}$ & $0.343 \pm 0.030^{\$, *}$ \\
\hline & Postoperative & $0.349 \pm 0.029 \#$ & $0.339 \pm 0.027^{\$,} \#$ \\
\hline \multirow{3}{*}{ QTc Interval } & Basal & $0.434 \pm 0.032 *$ & $0.422 \pm 0.033^{*}$ \\
\hline & Intraoperative & $0.430 \pm 0.030 \#, *$ & $0.417 \pm 0.029 \#$ \\
\hline & Postoperative & $0.427 \pm 0.028 \$$ & $0.414 \pm 0.027 \$$ \\
\hline \multirow{3}{*}{ QT Dispersion } & Basal & $0.047 \pm 0.016$ & $0.044 \pm 0.017$ \\
\hline & Intraoperative & $0.044 \pm 0.015^{*}$ & $0.042 \pm 0.015^{*}$ \\
\hline & Postoperative & $0.041 \pm 0.015 \#$ & $0.041 \pm 0.014 \#$ \\
\hline \multirow{3}{*}{ QTc Dispersion } & Basal & $0.057 \pm 0.020$ & $0.054 \pm 0.021$ \\
\hline & Intraoperative & $0.053 \pm 0.019^{*}$ & $0.051 \pm 0.019^{*}$ \\
\hline & Postoperative & $0.050 \pm 0.018 \#$ & $0.050 \pm 0.018 \#$ \\
\hline
\end{tabular}

*: Significant, $\mathrm{p}<0.0001$ (Basal vs. Intraoperative), \#: Significant, $\mathrm{p}<0.0001$ (Basal vs. Postoperative) $\$$ : Significant, $\mathrm{p}<0.05$ (Group A vs. Group B)

served when Group A compared to Group B at intraoperative and postoperative period $(\mathrm{p}<0.05)$. By applying Friedman test (Non-parametric Repeated Measures ANOVA test) in both group A and B, there was highly significant decrease in mean values of QT Interval when Basal compared to Intraoperative and Postoperative $(\mathrm{p}<0.0001)$.

QTe interval: When the mean values of QTc interval of Group A compared to Group B at basal intraoperative and postoperative period $(\mathrm{p}<0.05$, Student's Unpaired ' $t$ ' test) there was significant difference observed. By applying Friedman test (Non-parametric Repeated Measures ANOVA test), there was highly significant decrease in mean values of QTc Interval when Basal compared to Intraoperative and Postoperative $(\mathrm{p}<0.0001)$.

QT dispersion: There was no significant difference between mean values of QT dispersion when Group A compared to Group B at basal, intraoperative and postoperative ( $\mathrm{p}>0.05$, Student's Unpaired ' $\mathrm{t}$ ' test). By applying Friedman test (Non-parametric Repeated Measures ANOVA test), there was highly significant decrease in mean values of QT Dispersion and QTc
Dispersion in both group A and B, when Basal compared to Intraoperative and Postoperative $(p<0.0001)$.

QTe Dispersion: There was no significant difference between mean values of QTc dispersion when Group A compared to Group B at basal, intraoperative and postoperative ( $p>0.05$, Unpaired ' $t$ ' test,). By applying Friedman test (Non-parametric Repeated Measures ANOVA test), there was highly significant decrease in mean values of QT Dispersion and QTc Dispersion when Basal compared to Intraoperative and Postoperative $(\mathrm{p}<0.0001)$ in both group A and B.

Among the patients who complained of palpitation, 10 and 16 were from group A and group B respectively. No other adverse effects were observed.

\section{DISCUSSION}

It is currently thought that the cardiovascular effects of conventional adrenaline doses are of little practical concern, even in patients with heart disease [9]. However, even following usual precautions (e.g., aspiration, slow injection), sufficient adrenaline can be absorbed to cause sympathomimetic reactions such as apprehension, 
tachycardia, sweating and palpitation [10]. There also may be delayed wound healing, tissue edema, or necrosis after local anesthesia. These effects seem to occur partly because sympathomimetic amines increase the oxygen consumption of the tissue which leads to hypoxia and local tissue damage together with the vasoconstriction [3].

Dental practitioners use local anesthetic injections with various concentration of adrenaline. The local anesthetic was lignocaine $2 \%$ and adrenaline was used in the concentration of 1:80000 and 1:200000. The choice of use of anesthetic and vasoconstrictor combination was decided by the treating dental surgeon in the present study.

Age wise distribution seen in this study was, 50 $(33.33 \%)$ patients were between the ages of $18-40$ years in both groups. $67(44.67 \%)$ patients were between the ages of 41-60 years and the rest of 33 $(22.00 \%)$ patients were above 60 years of age. There was no significant association between age of the patients administered with lignocaine adrenaline combination. (Table no. 1)

$69(46.00 \%)$ patients in our study were females and the rest $81(54.00 \%)$ patients were males. There was no significant association between genders of the patients administered with lignocaine adrenaline combination. (Table no. 1) There was no association between age and sex of the patients with any of the ECG parameters

The results of Group A findings of Basal when compared to Intraoperative and Postoperative in terms of ECG parameters revealed significant decrease in PR interval, RR interval, QT interval, QTc interval, QT dispersion and QTe dispersion which appears to be due to adrenaline 1:80000 administered along with $2 \%$ lignocaine. Also, the same ECG parameters in Group B showed statistically significant decrease in PR interval, RR interval, QT interval, QTc interval, QT dispersion and QTc dispersion, with the basal readings were compared with intraoperative and postoperative. These decrease in all the ECG parameters in Group B with adrenaline 1:200000 combined along with lignocaine $2 \%$ is similar to Group A, thus shows the indirect or direct activity of adrenaline might be resulting in changes in above ECG parameters.

It was observed that there was no significant difference between mean values of PR Interval and RR Interval when Group A compared to Group B at basal, intraoperative and postoperative (Table no 3). Similarly, there was no significant difference between mean values of QT interval when Group A compared to Group B at basal $(p>0.05)$ while significant difference was observed when Group A compared to Group B at intraoperative and postoperative period (Table no. 3). There was significant difference between mean values of QTc interval when Group A compared to Group B at basal, intraoperative and postoperative period (Table no. 3).

The mean values of QT dispersion and QTc dispersion between Groups A compared to Group B at basal, intraoperative and postoperative showed non-significant difference as shown in table no. 3 .

The mean heart rate in each group was calculated from the RR Interval to minimize human error by investigator. There was no significant difference between mean values of Heart rate when Group A compared to Group $\mathrm{B}$ at basal, intraoperative and postoperative (Table no. 3 ). The mean heart rate although found to be significantly increased in both the groups from basal to postoperative but was always within normal range. This increase in heart rate may be contributed to the presence of adrenaline in drug combination.

Various studies have shown that there is a swift absorption of adrenaline [11-13] resulting in direct or indirect increase in heart rate which can be confirmed from the results of earlier studies. Salonen et al confirms that there is approximately 5 fold increase in plasma adrenaline levels and approximately 2 fold increase in noradrenaline levels during dental surgery, indicative of sympathetic activity [13]. The statistical minimal rise in heart rate in both the groups in present study may be due to the above stated theory of rise in endogenous adrenaline and noradrenaline. There was no clinically significant relevance of the above theory demonstrated in present study as the changes in the ECG parameters were within normal limits.

There had been infrequent reports of serious complications associated with use of lignocaine-adrenaline combinations in various dental procedures [14]. The adverse effects were noted in terms of cardiovascular morbidities in present study. The only morbidity was found to be palpitation and the heart rate in all the patients having palpitation was never above 105 beats $/ \mathrm{min}$. None of the patients in both the groups showed any electrocardiographic changes relevant to cardiac arrhythmias which can be determined by QT interval, QTc interval, QT dispersion and QTc dispersion and changes remained within normal limits. This signifies the safety of lignocaine-adrenaline combinations in all apparently healthy, non-cardiovascular compromised patients.

Godzieba et al reviewed 11 studies for safe use of local anesthesia with vasoconstrictor agents in cardiovascular compromised patients. The overall complication rate across studies was $15.5 \%$. The most frequent complications in cardiovascular compromised patients after dental local anesthesia with vasoconstrictor agent were ECG arrhythmias but a major part of the disclosed arrhythmias were clinically insignificant. They recommended ECG monitoring during use of local anesthetic with vasoconstrictor in cardiac compromised patients [15]. But the results of the present study do not support the findings of above study.

However, there were few studies found during literature search which differed from this view. Laragnoit et al [16] carried out a comparative study of plain lignocaine and lignocaine with adrenaline $(1: 100000)$ for locoregional anesthesia in cardiac patients. No differences were shown in blood pressure, heart rate and pulse oximetry values before, during and after local anesthesia injection between the two groups.

Arrhythmias observed before dental anesthesia did not change in shape or magnitude after treatment. It was concluded that lignocaine with adrenaline $(1: 100,000)$ provided effective local anesthesia and this treatment did not cause an increase in heart rate or blood pressure and did not cause any arrhythmic changes in patients with cardiac valvular diseases [16]. Results of the pre- 
sent study showed similar findings but with increase in heart rate without any clinical significance. Conrado et al also suggested that dental extractions performed under anesthesia with adrenaline $(1: 100000)$ does not imply additional ischemic risks, as long as performed with good anesthetic technique and maintenance of the pharmacological treatment prescribed by the cardiologist [17].

Concern is always over the use of the combination in cardiovascular compromised patients. Majority of the studies for safety of lignocaine adrenaline combination were done on cardiovascular compromised patients [1517].

Present study was focused on effects of lignocaine adrenaline combination on apparently healthy, noncardiovascular compromised patients. Emphasize was given to the effects of the drug combination on electrocardiogram.

There was significant decrease in all the ECG parameters studied from baseline to postoperative period in both the study groups. Based on the results it becomes evident that use of adrenaline along with lignocaine in both the concentration have shown increase in heart rate which is in concurrence with earlier studies. The mean increase in heart rate may be due to increase sympathetic activity and indirect release of endogenous catecholamines. There were differences in heart rate among the patients studied in both the groups. The vagal tone and baroreceptor sensitivity differ in each individual and may interfere with dose response relationship of adrenaline [18]. This explains the lack of correlation between so called endogenously released plasma adrenaline and its clinical manifestations which were revealed in present study showing no any clinically significant changes in ECG parameters and heart rate. It can be very well stated that effects of lignocaine-adrenaline combinations on ECG remains irrelevant clinically.

This study was undertaken primarily to find out the safety of Ligocaine-Adrenaline combination as local anesthetic in various dental operative procedures in Pravara Rural Hospital in terms of Electrocardiography.

The increase in heart rate although was statistically significant in both the groups, it was always within normal limits suggestive of no clinical significance. There was statistical significant decrease in QT and QTe interval, QT and QTc dispersion. The change in all these parameters was within physiologic range. All these relevant parameters for cardiac arrhythmias did not show any arrhythmogenic potential of lignocaine-adrenaline combination in both the groups. Both the combinations are comparable with each other in terms of ECG parameters with changes more with group A suggesting the effect of increased concentration of adrenaline. The change in the heart rate and ECG parameters in both the study group might be attributed to the presence of adrenaline in the combination. No cardiovascular morbidities were observed except palpitation.

\section{CONCLUSION}

The effects of lignocaine-adrenaline combinations on electrocardiographic parameters are minimal and clinically irrelevant. Both the combination appears to be safe to use in healthy individuals.

\section{Conflict of Interest: Declared none}

Acknowledgements: We thank the study participants. REFERENCES

[1] Katzung BG, Masters SB, Trevor AJ. Basic and Clinical Pharmacology. $11^{\text {th }} \mathrm{ed}$. The McGraw-Hill Companies; 2009.

[2] Malamed SF. Handbook of Local Anesthesia. 6th ed. Elsevier Inc.; 2013.

[3] Brunton LL, Chabner BA, Knollmann BC. Goodman \& Gilman's The Pharmacological Basis of Therapeutics. $12^{\text {th }}$ ed. The McGraw-Hill Companies; 2011.

[4] Covino BG. Toxicity and systemic effects of local anesthetic agents. In: Local Anesthetics. Strichartz GR, editor. Handbook of Experimental Pharmacology. Springer-Verlag, Berlin, 1987;81:187212.

[5] Tolas AG, Pflug AE, Halter JB. Arterial plasma epinephrine concentrations and hemodynamic responses after dental injection of local anesthetic with epinephrine. J Am Dent Assoc. $1982 ; 104: 41-3$

[6] Cryer PE. Physiology and pathophysiology of the human sympathoadrenal neuroendocrine system. N Engl J Med. 1980; 303:436-44

[7] Yagiela JA: Epinephrine and the compromised heart. Orofac Pain Manage. 1991; 1:5-8.

[8] Bazett HC, An analysis of time relation of electrocardiograms. Heart. 1920;7:353-67

[9] Jastak, JT, Yagiela, JA, Donaldson D, editors. Local anesthesia of the oral cavity. Philadelphia: WB Saunders; 1995.

[10] De Jong RH: Uptake, distribution, and elimination. In: de Jong RH, editor: Local anesthetics. St Louis: Mosby; 1994.

[11] Knoll-Köhler E, Frie A, Becker J, Ohlendorf D. Changes in plasma epinephrine concentration after dental infiltration anesthesia with different doses of epinephrine. J Dent Res. 1989; 68(6):1098-101.

[12] Troullos ES, Goldstein DS, Hargreaves KM, Dionne RA. Plasma Epinephrine Levels and Cardiovascular Response to High Administered Doses of Epinephrine Contained in Local Anesthesia. Anesthesia Progress. 1987 January.

[13] Salonen M, Forssell H, Scheinin M. Local dental anaesthesia with lidocaine and adrenaline: Effects on plasma catecholamines, heart rate and blood pressure. Int. J. Oral Maxillofac. Surg. 1988;17:392-4.

[14] Rosen E, Tsesis I. Surgical Anesthesia: When a Tool Becomes a Weapon. In: Tsesis I, editor. Endodontic Surgery: Prevention, Identification and Management. Springer; 2014: 53-60 
[15] Godzieba A, Smektala T, Jedrzejewski M, Sporniak-Tutak K. Clinical assessment of the safe use local anaesthesia with vasoconstrictor agents in cardiovascular compromised patients: A systematic review. Med Sci Monit. 2014; 20: 393-8

[16] Laragnoit AB, Neves RS, Neves ILI, Vieira JE. Locoregional anesthesia for dental treatment in cardiac patients: A comparative study of $2 \%$ plain lidocaine and $2 \%$ lidocaine with epinephrine $\quad(1: 100,000) . \quad$ Clinics. 2009; 64 (3):177-82

[17] Conrado VC, de Andrade J, de Angelis GA, de Andrade AC, Timerman L, Andrade MM, et al. Cardiovascular Effects of Local Anesthesia with Vasoconstrictor during Dental Extraction in Coronary Patients. Arq Bras Cardiol. 2007 ; $88(5)$ : 446-52

[18] Taggart E, Hedworth-Whitty R, Carruthers M, Gordon E. Observations on electrocardiogram and plasma catechol-amines during dental procedures: the forgotten vagus. Br. Med. J. 1976; 2:787-9. 